\title{
O PARADOXO DO SAGRADO - UM ESTUDO DA MÍDIA INSTITUCIONAL RELIGIOSA
}

\section{Luís Mauro Sá Martino*}

\begin{abstract}
RESUMO: Este artigo delineia alguns aspectos da 'guerra santa' conforme é apresentada nos jornais religiosos. As religióes universais têm como princípio a fraternidade universal; todavia, ao se apresentarem no campo religioso, o discurso da tolerância é substituído por um conflito no qual cada igreja tenta eliminar a concorrência e alcançar a posição hegemônica de definição do 'sagrado', do 'profano' e do comportamento do fiel. Para tanto, as igrejas precisam adequar seu discurso e sua linguagem ao meio de comunicação utilizado com vistas à obtenção da melhor relação custo-benefício para arregimentar fiéis. A partir das noçôes de 'campo' e 'habitus', de Pierre Bourdieu, pode-se ver como a ação social de todas as igrejas leva a esta situação paradoxal.
\end{abstract}

As religióes ocidentais têm como princípio doutrinário a fraternidade universal. Uma breve consulta aos principais tratados teológicos confirma essa afirmação, sem a necessidade de uma demonstração exaustiva. Todavia, quando as instituiçôes religiosas se expressam pela mídia, impressa ou eletrônica, um paradoxo se manifesta: em vez da fraternidade irrestrita, buscam a deslegitimação de outros grupos religiosos, numa verdadeira guerra pelo controle do imaginário social (VIEIRA, 1997). Além disso, devem adaptar sua linguagem aos padrôes da comunicação de massa, aliando a contundência do discurso religioso às características específicas do discurso midiático. Obviamente, a existência desse paradoxo é condicionada pela disposição ao proselitismo de cada religião e sua reprodução no meio social (DURKHEIM, 1997). Quanto mais acirrada a disputa pelo domínio do campo (BouRDIEU, 1980), maior a alocação de um capital religioso-simbólico para conseguir a hegemonia (BOURDIEU, 1992), especialmente na sua veiculação pela mídia.

O paradoxo entre o discurso da fraternidade universal e o discurso da violência contra as instituições não é novo: dezenas de guerras religiosas na História o provam e os acontecimentos atuais o confirmam. A esse respeito, já no século XVII, Kant (1994: 17) afirmava que "quando uma igreja, como habitualmente
PALAVRAS-CHAVE: mídia; religião; linguagem; Bourdieu.

*Jornalista. Mestre em Ciências Sociais pela PUC-SP. Professor de Comunicação Comparada da Faculdade Cásper Líbero. 
acontece, se faz passar pela única universal, então quem não reconhece sua fé eclesial é por ela denominado infiel e odiado de todo o coração".

No passado e no presente, a deslegitimação pelos símbolos prepondera sobre a violência física na luta pelo monopólio de definição do sagrado. O uso da mídia como espaço privilegiado de luta, porém, é uma especificidade do século atual. O episódio da agressão a uma imagem de Nossa Senhora Aparecida pelo pastor Sérgio Von Helde, em 1995, iniciou uma discussão sobre a guerra santa existente no país. O tema, que fez parte da agenda pública durante mais de um mês, demonstrou que a chamada 'guerra santa' é, antes de tudo, uma 'guerra simbólica', cada vez mais midiatizada, e o capital simbólico é alocado para a definição dos bens doutrinários legítimos. (BOURDIEU, 1992: 57)

O fato de a 'batalha simbólica' se travar no âmbito midiático abre espaço para a análise das relações entre a linguagem religiosa e os meios de comunicação. No uso destes instrumentos, as religiōes 'testam' a eficácia de seu discurso, adequando a linguagem religiosa à da mídia. $\mathrm{O}$ estudo que aqui utilizamos como base empírica de reflexão ${ }^{1}$ pretende responder a algumas questóes sobre essa batalha simbólica: como são os ataques? qual a religião mais agressiva em relação às demais? quem é o mais atacado? quais as relações entre religião e política? qual a linguagem utilizada?

O jornal institucional é um canal privilegiado de comunicação entre os fiéis e os representantes da instituição, no qual os temas podem ser abordados com mais abrangência, as opiniōes e idéias são expostas com clareza e as informações podem ser direcionadas para transmitir ao fiel exatamente o que se quer. Entre os veículos analisados, as matérias opinativas explícitas são majoritárias em detrimento do chamado 'jornalismo informativo', em que predominam as notícias. Estas, conforme veremos detalhadamente, referem-se basicamente a três campos: o mundo cotidiano, as atividades da instituição e os depoimentos.

A análise da linguagem dos produtos informativos religiosos, sejam informativos, interpretativos ou opinativos, denuncia os termos do paradoxo em questão: a proposta inicial de fraternidade universal transforma-se, em sua adaptação para a linguagem da mídia religiosa, em fraternidade institucional, restrita aos membros de determinado grupo (Berger \& Berger, apud Foracchi \& MARTins, 1982: 193-200).

Há dois tipos básicos de paradoxos encontrados na mídia religiosa: contradições entre conteúdos informativos de um mesmo veículo e entre o conteúdo dos produtos informativos e a doutrina oficial objetivada nos livros sagrados e em suas exegeses reconhecidas. O paradoxo existente entre conteúdos de um mesmo veículo é cons-
${ }^{1}$ Pesquisa realizada como Trabade Comunicação So(1998. existentes na cidade de São Paulo - Católicos, Evangélicos, Espíritas e Judeus. Os muçulmanos, nossuirem um universo postos à margem do estudo. 
tatado em quase todos os jornais. Matérias, artigos e colunas pregam a fraternidade e o bom entendimento entre todos. Articulistas e colunistas pedem a paz, ao passo que, em páginas próximas, exibem-se ataques às instituições concorrentes.

Sabe-se que a eficácia simbólica da dominação é tanto maior quanto menos explícitos estiverem os instrumentos de controle (Bourdieu, 1980: 209). A linguagem dos jornais religiosos tende a dissimular ao máximo - com algumas exceções - os ataques. O sentido da concorrência permanece subjacente ao conjunto dos textos, muitas vezes relacionado com a propaganda da própria instituição. As obras de caridade, as atividades institucionais, as façanhas de determinados membros, as interpretações 'corretas' de determinados assuntos e o poder da instituição - em detrimento das instituições concorrentes, já que apenas uma instituição pode opor-se a outra (BERGER \& LUCKMANN, 1976: 79) - estão presentes, com maior ou menor intensidade, em todos os veículos.

O público de um jornal religioso é tendencialmente restrito aos freqüentadores da instituição. Sua divulgação é feita, principalmente, por meio de relações interpessoais e na relação apóstolo-fiel. Mesmo quando o jornal é vendido em bancas - caso da Folha Espirita e da Vinde -, atende a segmentos especializados, permanecendo ignorado por todos os outros. A imprensa religiosa procura reforçar o sentimento já existente no fiel (Weber, 1987). Como afirma Bourdieu (1992: 36), "a religião contribui para a imposição (dissimulada) dos princípios de estruturação da percepção e do pensamento do mundo”. Na imposição dissimulada de uma visão particular de mundo - incluindo os ataques à concorrência - reside a força da coerção simbólica. Mais sentida do que propriamente identificada (Bourdieu, 1980), ela é secundada por outras táticas para reforçar sua imagem de única visão de mundo possível. A 'objetividade' do jornalismo reforça a ilusão de que a mensagem institucional, seja a auto-enaltecedora ou aquela que critica a concorrência, nada mais é do que a 'verdade', o 'fato'.

Servindo-se de fatos concretos, mas devidamente selecionados, ocorridos no seio da instituição ou no domínio público, os meios fazem crer na evidência das posições doutrinárias da instituição sem necessariamente explicitá-las - utilizando, para tanto, a alegada objetividade jornalística. Nesse particular, Tuchmann (apud TRAQUINAS, 1993) mostra que o discurso da objetividade permite ao jornalista fugir de suas responsabilidades enquanto produtor. Na mesma linha, Barros Filho (1995) afirma que a aparência de objetividade informativa - a indiscutibilidade do 
real - esconde a seleção temática, léxica e estilística inerente a qualquer processo de comunicação e legitima pelo óbvio, estruturando, conforme afirma Hackett (apud TRAQUinas, op. cit.), os acontecimentos.

A rigor, a mídia religiosa se serve de temas da agenda pública e temas institucionais, coletivos ou individuais, adaptando-os à linguagem específica de cada religião. A agenda religiosa concentra temas institucionais, que dizem respeito ao grupo de fiéis e temas da agenda pública institucionalizados. Assim, o agendamento temático da mídia religiosa suscita discussões entre os fiéis sobre temas que se refiram exclusivamente à instituição ou que tenham sido agendados de maneira exaustiva por toda a mídia. A maior parte do elenco temático utilizado pela mídia religiosa refere-se a temas e acontecimentos relativos à instituição religiosa a que pertencem o jornal e a revista analisados.

Os vetores que orientam a agenda institucional podem ser subdivididos em três grupos principais: a) as atividades da instituição, de rotina e extraordinárias - os cultos, os ritos de iniciação, as atividades pedagógicas de difusão da doutrina, as obras, as realizaçōes - não somente espirituais, mas materiais - da instituição são divulgadas como prova da legitimidade de suas ações (BERGER \& BERGER, apud ForaCCHI \& MarTins, 1982 e Bourdieu, 1998); b) as normas de conduta - o comportamento sugerido, requisitado ou até exigido pela instituição é apresentado por meio de casos concretos (de mais fácil percepção) ou de regras abstratas aplicáveis a todos os casos por elas previstos. Os editoriais, geralmente escritos pelos profissionais da religião, são o espaço mais usual para a explicitação das normas religiosas; c) as explicações doutrinárias e desenvolvimento de questôes referentes à teologia desta ou daquela instituição têm, na mídia impressa, um espaço privilegiado de divulgação. Conceitos religiosos abstratos podem ser explicados com vagar, em uma linguagem específica do grupo religioso, auxiliando a compreensão dos adeptos. Artigos opinativos que ataquem diretamente as demais instituiçôes não são raros, embora apareçam em menor número que os depoimentos, estes usados fartamente para agredir os concorrentes.

Não obstante, vários jornais e revistas dedicam este espaço à elucidação de temas pertencentes exclusivamente à respectiva religião, evitando quaisquer relações com grupos políticos, trabalhando com a agenda institucional unicamente para divulgar as atividades do movimento, discutir e analisar dúvidas doutrinárias, ou ainda 'repreendendo' os seguidores e apresentando normas de conduta compatíveis 
com a religião professada.

Nem todos os temas tratados pela mídia institucional religiosa são doutrinários ou dizem respeito às atividades da instituição. Os veículos religiosos, costumeiramente, servem-se de temas da agenda pública, isto é, aqueles 'impostos' pela mídia informativa generalista. A institucionalização dos temas da agenda pública estabelece uma fronteira simbólica interpretativa entre a instituição e o que lhe é exterior. Esta fronteira pode ser explícita, quando a interpretação institucional é manifesta, ou implícita, quando o único indício de institucionalização do tema é a sua presença na mídia institucional. Os temas de atualidade, quando compatíveis, são interpretados à luz da doutrina religiosa. Esses assuntos, reaproveitados pela mídia institucional, percorrem todas as editorias do jornalismo generalista - política interna, política internacional, economia, esporte etc.

As relações existentes entre os campos político-religiosos também são temas institucionalizados da agenda pública. Uma mesma ação do presidente da República, quando tratada por diferentes veículos religiosos, assume conotaçôes diferentes, não raro contraditórias. Em determinadas publicações, como na Folha Universal e na Resenha Judaica, a ascendência do campo político sobre o religioso assume proporções de tal ordem que a religião passa a ser mero pano de fundo para a discussão de temas políticos e sociais, ataques a esta ou àquela corrente ideológica ou apoio a grupos de esquerda ou direita. A relação política/religião pode ser mais ou menos explícita de acordo com as normas institucionais. Em alguns casos estudados, o movimento acontece em sentido oposto: evita-se sempre a intersecção dos dois campos.

A necessidade de contundência persuasiva não é ontológica, mas reflexiva. Seduzir novos fiéis significa não permitir que eles se dirijam a instituições concorrentes. As matérias analisadas permitem constatar a existência de dois tipos diversos de matérias jornalísticas veiculadas. As primeiras dizem respeito à postura institucional da mídia, ou seja, o agendamento de temas relativos exclusivamente aos fiéis, como atividades particulares da instituição, seu apostolado, matérias explicativas da doutrina; as demais versam sobre a postura reflexiva da instituição,

isto é, suas relações com o campo político e as menções relativas às instituições concorrentes. Não é demais lembrar que essas características, embora em graus diferentes, estão presentes em todos os veículos analisados. 
Se a mídia e a igreja constroem e impõem representaçōes do mundo social, servindo-se de uma recepção ritualizada, de processos de inculcação e de mecanismos de aculturação eficazes a médio e longo prazos, não é de espantar que, freqüentemente, as instituições religiosas se utilizem do jornal como instrumento de educação, como maneira de introduzir comportamentos e dirigir a socialização dos fiéis para os padrōes estabelecidos segundo a ideologia do grupo. (FreiTAG, 1986)

A linguagem didática dos jornais é mais contundente de acordo com o código utilizado na transmissão da mensagem. Na transmissão da mensagem educativa pelos meios, os códigos utilizados tendem a ser diretos, ainda que não explícitos. E raro observar uma matéria dizendo "você deve", "o fiel deve". Não obstante, exemplos de comportamentos 'certos' - ou dos comportamentos 'errados' e suas consequiências - são utilizados com freqüência, ressaltando a independência contextual, o que, para Tugendhat (1997: 38), resulta em uma contradição lógica.

Com efeito, DeFleur \& Ball-Rokeach (1993) indicam que a construção de significados com vistas a mudanças - ou reforço - de comportamento é uma das atribuiçôes da mídia, sendo esta responsável pela inculcação de uma determinada representação, mais do que de um padrão de comportamento. A representação, em determinados casos - os depoimentos, por exemplo - usam como argumento primeiro a situação verídica pela qual passou alguém já 'salvo'.

O divertimento não é visto como leviano desde que feito dentro da instituição. A realidade 'ruim' que aterroriza os fiéis é contraposta aos cultos ou espaços de divertimento nas igrejas. Sendo assim, o soldado apostólico encontra, ao mesmo tempo, doutrina e diversão. Como explica Jameson (1997: 74):

... divertir significa sempre não pensar sobre qualquer coisa, esquecendo mesmo onde ele [um determinado assunto] é mostrado. A impotência é a sua própria base. É na verdade uma fuga, mas não, como se afirma, uma fuga da realidade ruim, mas da última resistência que esta realidade ainda deixa subsistir.

Não raro, a doutrina religiosa, em redefinição ininterrupta, serve-se de algum caso concreto, descrição de uma história pessoal ou de um depoimento para associá-los a dogmas, previsōes ou simples pontos de vista de autoridades religiosas. O recurso é quase sempre o da reificação, ou da generalização.

Outra estratégia é a radicalização do contraste. Os depoimentos selecionados pelos meios sempre destacam a passagem do 'mal absoluto' para o 'bem' da insti- 
tuição. $\mathrm{Na}$ análise de 50 (cinqüenta) depoimentos veiculados na Folha Universal, nenhum destacava a conversão de um indivíduo que tivesse uma conduta de vida normal para os padrões cristãos; todos estavam 'perdidos' quando procuraram a instituição. Poucos testemunhos dos depoentes declararam que estes se dirigiam à instituição religiosa por curiosidade ou por algum tipo de revelação divina. É sempre um fator externo que servirá de base ao depoimento, o fio condutor da pessoa a uma determinada igreja e não a outra.

Atendendo às imposições necessárias para seu agendamento no meio, os depoimentos obedecem a três fatores que determinam sua presença na mídia religiosa:

1. a personalização do conteúdo, ou seja, o uso de exemplos e situações próximas ao cotidiano e não abstratas. Todas as pessoas já ficaram doentes, já sentiram dores ou se viram diante de problemas de saúde, ao menos uma vez na vida. O depoimento que mostra a interferência divina por intermédio da instituição na resolução dessas dificuldades encontra perfeita receptividade no leitor, que reconhece, na notícia, uma situação já experimentada por ele;

2. a dramatização, quando existe um conflito entre posições antagônicas. A maior parte dos depoimentos refere-se ao combate entre o fiel e as dificuldades da existência (DURKHEIM, 1998: 459), com duas variáveis principais: a ação ou não de entidades negativas como elemento desencadeador de ruptura da vida normal; o papel preponderante da instituição com o objetivo de apoiar e auxiliar o fiel em seu retorno à vida normal, amparado pela instituição;

3. a dinamização do tema, fazendo com que o receptor possa constatar uma ação ou acontecimento. Os depoimentos são cheios de lances, desfechos e desenlaces inesperados, na mesma linha temática que explica o sucesso dos folhetins do século XIX. (ECO, 1997)

A especificidade que distingue o depoimento do folhetim simples é a sua apresentação como notícia. O fato espetacular, o salvamento no último minuto, a abnegação da esposa sofredora, todos esses lances literários são apresentados como notícias, fatos inéditos e objetivos, como manifestação plena da potência de determinados membros da instituição nas situações-limite. Ao contrário dos produtos de criação, que assumem explicitamente sua dimensão ficcional, o depoimento é apresentado como o relato frio do real, da experiência da vida real. A realidade, o vazio existencial (HOFFER, 1968: 82) e familiar, os vícios e desejos homicidas são um 
apanhado geral das muitas desgraças a que pode estar submetida uma pessoa, seja ela crente ou não. Os evangélicos, segundo eles próprios, estão com Jesus e somente Nele está a salvação eterna, assim como o fato de pertencer a determinada igreja discrimina quem está sob o "dossel sagrado" (BERGER, 1974). O impossível para a lógica e para a razão - um caso de cura de doença terminal, por exemplo - acontece quando um fiel revela suas curas, que não são apenas existenciais, mas também físicas. Sua solução via oração significa o maior trunfo dos méritos da instituição, já que tal foi a fé do agente da igreja e do convertido que o impossível acontece, que um Ser onipotente não ficou indiferente aos apelos de seus filhos, caindo sobre a igreja o mérito de ser 'donatária do Senhor' em qualquer circunstância.

Além dessa postura institucional, pela qual são valorizados os aspectos internos da instituição, existe of front externo, ou seja, os ataques de uma instituição a outra e as relações entre instituições religiosas e políticas.

\section{Postura reflexiva}

A postura institucional das religiōes trata das atividades institucionais, do comportamento do fiel e de suas relaçôes com a doutrina. Mesmo quando existem mençõoes ou ataques a outras instituiçôes - particularmente nos casos de depoimentos - eles são fruto de posturas institucionais. As mençōes às demais concorrentes são explícitas; têm o objetivo de deslegitimar as instituições paralelas, buscando o monopólio do campo religioso. A postura reflexiva das instituições, conforme observamos, não se manifesta somente no trato com outras instituiçôes. A relação existente entre os campos político e religioso é o tema principal de algumas publicações.

Existem dois extremos nessa postura: desde a Folha Espírita, na qual há uma única matéria referindo-se - de forma não explícita - a evangélicos, católicos e judeus, até a Folha Universal, em que os ataques são o prato principal da publicação. Contra espíritas e católicos, a Folha Universal reserva espaços constantes. Para os espíritas há sempre trechos do livro Orixás, Caboclos e Guias, Deuses ou Demônios?, de autoria do próprio Edir Macedo, líder da igreja. Contra os católicos há, em geral, depoimentos que procuram revelar 'podres' da Igreja Católica.

A postura reflexiva desta igreja, em particular, manifesta-se na construção não 
em que a preocupação é mostrar que a pessoa, ao esquecer-se de Deus, realmente viu e conheceu o mal, e pode, com a ajuda da Igreja Universal do Reino de Deus (IURD), vencê-lo. Nenhuma palavra há sobre o livre-arbítrio ou possibilidades de escolha por parte do fiel, que é maniqueisticamente jogado entre as forças do bem e do mal. As manifestaçôes do mal sempre começam ou passam por um centro espírita, na visão da Universal. É dos pais-de-santo, guias e exus a culpa de todas as dificuldades enfrentadas pelas pessoas que chegam à IURD.

Além do paradoxo evidente entre a fraternidade pretendida e a eliminação da concorrência, fica patente que o discurso religioso assume formas diversas em sua intersecção com o campo político, espaço privilegiado de disputas. Fica claro que a associação de uma religião com determinado universo político implica seu alinhamento em relação a diversas questóes, cujo âmbito ultrapassa o puramente religioso.

É notório, por outro lado, que esse alinhamento prevê a entrada de mais elementos na disputa pelo controle do campo e atrela, de maneira explícita, a intenção místico-religiosa no trato de questões seculares, reforçando com o discurso religioso as posições políticas. A mídia religiosa, aliando dois discursos de legitimação, o religioso e o da mídia - um por sua condição de dogma revelado, outro por sua pretensão de objetividade -, procura reforçar esta ou aquela posição, com cuidado para que tais questôes possam ter aparência e relevância doutrinárias que justifiquem sua presença em um veículo religioso. Dessa forma, os agentes da luta em questão disponibilizam toda sua aparência de objetividade e isenção para imporem, por meio desses artifícios, uma determinada representação do mundo. (BOuRdieu, 1998: 55)

As relações de apoio ou oposição ao governo caracterizam, nas publicações institucionais, as relações entre os campos político e religioso. No caso específico da oposição, vale destacar que certas publicações assumem uma postura explícita de crítica ao governo, mostrando que o alinhamento dos grupos políticos e religiosos dominantes não é a regra, como pretendia a análise marxista.

Antonio Gramsci (2000) foi sem dúvida o pensador marxista que mais consagrou doutrina à religião. Tendo como base de análise a sociedade italiana, em que o catolicismo exercia grande influência, Gramsci se opunha ao mecanicismo simplista da interpretação marxista, que considerava a religião apenas uma imposição pertencente à superestrutura. $\mathrm{O}$ pensador italiano distingue, na superestrutura, 
dois elementos: a sociedade política, apoiada na coação, e a sociedade civil, que se vale da persuasão. Esta última, segundo ele, seria responsável pela hegemonia da classe dominante nas sociedades capitalistas.

Nesta mesma linha crítica da teoria do reflexo, o francês Louis Althusser (1974) também discriminou na superestrutura dois elementos: os aparelhos repressivos de Estado (A.R.E) e os aparelhos ideológicos de Estado (A.I.E). Enquanto a análise marxista tradicional conferia maior importância aos A.R.E, Althusser analisava o papel social dos A.I.E., destacando que a igreja sempre foi o A.I.E dominante, enquanto legitimadora da resignação. Segundo o modelo althusseriano, um aparelho ideológico de Estado se constitui "num certo número de realidades que se apresentam ao observador imediato sob a forma de instituiçóes distintas e especializadas". (ALTHUSSER, 1974: 147)

Se as instituições religiosas muitas vezes são incitadoras de resignação em relação à ordem vigente, a análise dos meios religiosos realizada confirma que nem sempre isso ocorre. Em alguns casos, há uma clara posição crítica dos elementos do campo religioso com relação aos dominantes do campo político. Deve-se notar, porém, que as relações entre política e religião são apresentadas sempre no contexto das disputas institucionais. É possível encontrar, por exemplo, apreciações críticas da Igreja Universal ao governo FHC. A leitura da notícia, porém, revela que o ataque se refere ao suposto 'favorecimento' da Igreja Católica pelo governo, mostrando a existência de uma sobreposição entre política e religião, sempre direcionada à acumulação de 'capital simbólico' (BouRdieu, 1980), passível de utilização, futuramente, em outras disputas.

A luta pelo domínio do campo religioso é uma realidade. Os meios de comunicação oferecem diversos exemplos de como as diferentes idéias religiosas se digladiam na conquista de novos adeptos. Essa violência, ainda que não beire os excessos dos fundamentalistas, está sempre presente, principalmente no campo simbólico, cujo espaço de combate é representado pela mídia.

Logo, temos a comprovação do paradoxo inicial, mas devidamente quantificado e analisado. Note-se que a violência simbólica, de cujo uso indiscriminado a mídia comum é freqüentemente acusada, faz-se presente na mídia religiosa com o reforço de um conjunto de símbolos inerentes às práticas religiosas. 
ABSTRACT: This paper outlines some aspects of this 'holy war' as it is presented in the religious newspapers. All the religious have the universal fraternity as a special doctrinal point. However, when these religions are introduced in the religious field, their tolerance discourse is replaced by a conflict in which each church tries to eradicate its rivals' discourse and reach the hegemonic prerogative in order to define both the 'holy' and the 'profane' as well as their follower's social behavior. From Pierre Bourdieu's key concepts, one can realize how all churches' social actions lead not only themselves but also their followers to this paradoxical situation.

\section{REFERÊNCIAS BIBLIOGRÁFICAS}

AlthUsSer, Louis. Ideologia e aparelhos ideológicos do Estado. Lisboa: Livraria Presença, 1974.

Alves, Rubens O que é religiāo? São Paulo: Ars Poetica, 1996.

BACCEGA, Maria A. Do texto editado à construção do mundo. Comunicação e educação, São Paulo: Moderna, n. 1, set./dez. 1994.

Barros Fo, Clóvis. Ética na comunicação. São Paulo: Moderna, 1995.

Berger, P. O dossel sagrado. Petrópolis: Vozes, 1974.

Berger, P. \& Berger, B. O que são instituiçōes sociais. In: Foracchi, M. e Martins, J. Sociologia e sociedade. Rio de Janeiro: Livros Técnicos e Científicos, 1981.

Berger, P. \& Luckmann, Thomas. A construção social da realidade. Petrópolis: Vozes, 1976.

Bourdieu, Pierre. Le sens pratique. Paris: Minuit, 1980. . A economia das troca simbólicas. São Paulo: Persepectiva, 1992. O poder simbólico. Rio de Janeiro: Bertrand Brasil, 1998.

Questôes de sociologia. Rio de Janeiro: Marco Zero, 1983.

Razóes práticas. Campinas: Papirus, 1997.

Camargo, C. P. F. Católicos, protestantes, espiritas. Petrópolis: Vozes, 1973.

DeFleur, M. \& Ball-Rokeach, S. Teorias da comunicação de massa. Rio de Janeiro: Zahar, 1993.

Durkheim, Émile. As regras do método sociológico. São Paulo: Martins Fontes, 1995.
KEY WORDS: media; religion; legitimization; Bourdieu.

\section{$\mathrm{E}$}

C

C

o

$\mathrm{R}$ 
. As formas elementares da vida religiosa. São Paulo: Martins Fontes, 1996. ECO, Umberto. O super-homem de massa. São Paulo: Perspectiva, 1997.

Foracchi, Marialice \& Martins, José S. Sociologia e sociedade. Rio de Janeiro: Livros Técnicos e Científicos, 1981.

Gramsci, Antonio. Cadernos do cárcere. Rio de Janeiro: Civilização Brasileira, 2001. v. I-IV.

Hackett, R. Declínio de um paradigma? A parcialidade e a objetividade nos estudos dos media noticiosos. In: TRAQUINAS, N. Jornalismo: questóes, teorias e histórias. Lisboa: Vega, 1993. p. 101-132.

HofFer, E. Fanatismo e movimentos de massa. Rio de Janeiro: Lidador, 1968.

Jameson, Fredric. O marxismo tardio. São Paulo: Unesp/Boitempo, 1997.

Kant, Emmanuel. A religião nos limites da simples razão. Lisboa: Edições 70, 1992.

KunCZIK, Michel. Conceitos de jornalismo. São Paulo: Edusp, 1997.

Littlejohn, S. Fundamentos teóricos da comunicação humana. Rio de Janeiro: Zahar, 1982.

Martino, Luís M. S. A santa guerra simbólica. Ética e meios, São Paulo: Moderna, n. 2, 1997. Boletim do Centro de Estudos de Ética na Comunicação.

Medina, Cremilda. Profissão jornalista - responsabilidade social. Rio de Janeiro: Forense-Universitária, 1982.

Morin, Edgar. Cultura de massas no século XX. Rio de Janeiro: Forense-Universitária, 1986.

Paillet, M. Jornalismo, o quarto poder. São Paulo: Brasiliense, 1986.

Ribeiro, Jorge C. Sempre alerta. São Paulo: Olho d'Agua/Brasiliense, 1994.

Santos, J. Comunicação. Lisboa: Difusão Cultural, 1992.

TRaQUINAS, N. Jornalismo: questões, teorias e histórias. Lisboa: Vega, 1993.

TuCHMAn, G. A objetividade como ritual estratégico. In: TraquINAS, N. Jornalismo: questôes, teorias e histórias. Lisboa: Vega, 1993.

Tugendhat, Ernst. Liçôes sobre ética. Petrópolis: Vozes, 1997.

Valle, Edênio (org.). A cultura do povo. São Paulo: Cortez e Moraes/Educ, 1979.

VIEIRA, A. Imaginário, ficção, cotidiano: termos da mesma equação? Comunicação e Educação, São Paulo: Moderna, n. 9, maio/ago. 1997, p. 94. 